(6)

OPEN ACCESS

\title{
A practical guide to thiopurine prescribing and monitoring in IBD
}

\author{
Ben Warner, ${ }^{1}$ Emma Johnston, ${ }^{2}$ Monica Arenas-Hernandez, ${ }^{3}$ \\ Anthony Marinaki, ${ }^{3}$ Peter Irving, ${ }^{2}$ Jeremy Sanderson ${ }^{2}$
}

\begin{abstract}
${ }^{1} 1$ st Floor College House, St Thomas' Hospital, London, UK ${ }^{2}$ Department of

Gastroenterology, Guy's and St Thomas' NHS Foundation Trust, London, UK

${ }^{3}$ Purine Laboratory, Viapath, St Thomas' Hospital, London, UK
\end{abstract}

\section{Correspondence to} Dr Ben Warner, 1st Floor College House, St Thomas' Hospital, Westminster Bridge Road, London, SE1 7EH, UK; B.warner@uclmail.net

Received 27 July 2016 Revised 05 August 2016 Accepted 08 August 2016 Published Online First 29 August 2016

\section{CrossMark}

To cite: Warner $B$, Johnston $E$, Arenas-Hernandez $\mathrm{M}$, et al. Frontline Gastroenterology 2018:9:10-15.

\begin{abstract}
Thiopurines are often the mainstay of treatment for many patients with inflammatory bowel disease. As such, a general understanding of the evidence behind their use and of their metabolism is extremely useful in clinical practice. This review gives a practical overview of thiopurine metabolism, the importance of thiopurine S-methyltransferase testing prior to the start of therapy and the monitoring of thioguanine nucleotide levels while on treatment, guiding a personalised approach to optimising thiopurine therapy.
\end{abstract}

\section{INTRODUCTION}

Inflammatory bowel disease (IBD) is a chronic inflammatory disorder of the gut, divided into two main diseases, ulcerative colitis (UC) and Crohn's disease (CD).

Over the last decade there has been a shift in paradigm of the treatment of IBD with a 'top down' or 'rapid step-up' approach aimed at altering the natural history early in the course of the disease. Newer drugs, especially biologics, are being used for the treatment of IBD, and existing drugs such as thiopurines are being used more effectively by guiding individual dosing according to pharmacogenetic data and monitoring of drug metabolite levels.

Sixty per cent of patients with IBD receive thiopurines (azathioprine (AZA), mercaptopurine (MP) and to a lesser extent tioguanine) with proven efficacy in maintaining steroid-free remission. ${ }^{1}$ Although the evidence for the use of thiopurines in UC is not as strong as in patients with $\mathrm{CD}$, it has been demonstrated that in patients with steroiddependent UC, 53\% achieved steroid-free remission on AZA compared with 21\% on aminosalicylates. ${ }^{2}$ Therefore, thiopurines are recommended once a patient has required two courses of steroids within a year. ${ }^{3}$ Thiopurines are commenced earlier in CD, where aminosalicylates play little or no role, and have been demonstrated to reduce the need for surgery by $40 \% .{ }^{4}$ The SONIC (Study of Biologic and Immunomodulator Naive Patients in CD) trial study showed the benefit of thiopurines in addition to antitumour necrosis factor (TNF) agents in the treatment of $\mathrm{CD}$, most likely through reduced formation of antidrug antibodies against anti-TNF agents. ${ }^{5}$

Up to a third of patients have to stop thiopurines due to side effects, the main concerns being leucopenia (1.3-12.6\%), hepatotoxicity (4\%), pancreatitis (3\%) and gastric intolerance $(1.3-6 \%){ }^{6}$

Thiopurine S-methyltransferase (TPMT) activity influences the incidence of adverse effects, particularly bone marrow toxicity, however, there is no association with hepatotoxicity or pancreatitis. ${ }^{8}$

\section{THIOPURINE METABOLISM}

The prodrug AZA is converted non-enzymatically by biogenic thiols, including glutathione, to MP with the release of methyl-4-nitro-5-imidazole. Following uptake by transporters, MP undergoes metabolism by three competing pathways (see figure 1) to form the active metabolite, thioguanine nucleotides (TGNs) which function as rogue nucleic acids, disrupting the DNA replication of the most rapidly dividing cells such as activated $\mathrm{T}$ cell lymphocytes where TGN concentrations have been found to be higher and where genes involved in $\mathrm{T}$ cell immunity have been shown to be downregulated by AZA. ${ }^{9}$

\section{THIOPURINE S-METHYLTRANSFERASE}

Methylation of MP by TPMT is a critical step in thiopurine metabolism. It was first 


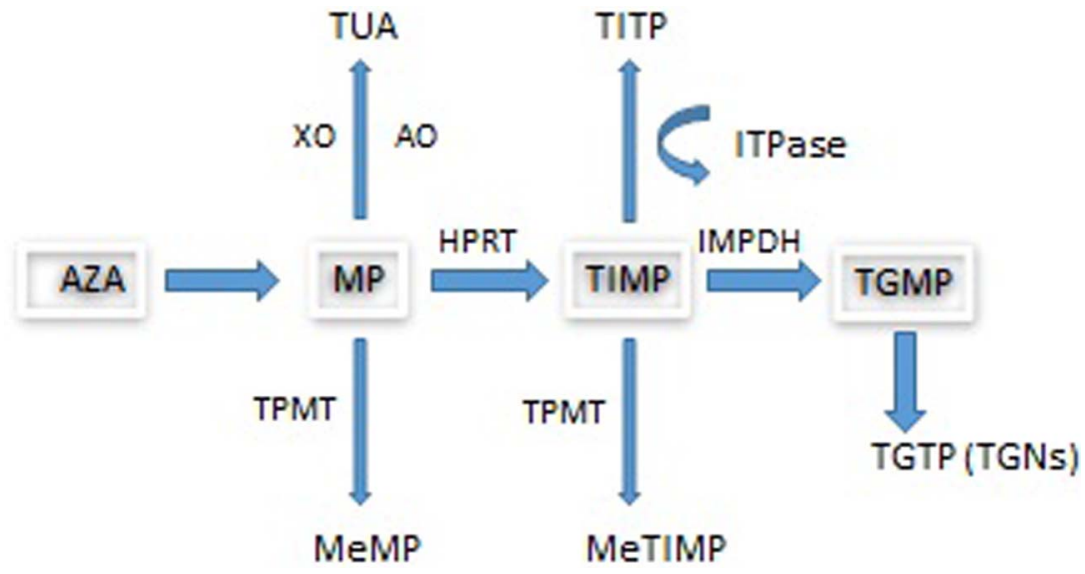

Figure 1 Azathioprine metabolism. AO, aldehyde oxidase; AZA, azathioprine; HPRT, hypoxanthine phosphoribosyltransferase; IBD, inflammatory bowel disease; IMPDH, inosine monophosphate dehydrogenase; ITPase, inosine triphosphatase; MeMP, methylmercaptopurine; MeTIMP, methylthioinosine monophosphate; MP, mercaptopurine; TGMP, thioguanine monophosphate; TGN, thioguanine nucleotide; TGTP, thioguanine triphosphate; TIMP, thioinosine monophosphate; TITP, thioinosine triphosphate; TPMT, thiopurine S-methyltransferase; TUA, thiouric acid; $X O$, xanthine oxidase. The metabolism of MP involves three competing pathways: the first being degradation to TUA which is then excreted, the second is through methylation by TPMT into MeMP, and the third is the breakdown of MP into TIMP catalysed by HPRT. TIMP is then further metabolised via IMPDH into TGMP. Kinases convert this into the TGNs. Approximately $15-20 \%$ of patients with IBD demonstrate hypermethylation when treated with thiopurines. This means that during thiopurine metabolism, methylated thiopurine metabolites are preferentially produced instead of TGNs.

noted in the 1980s that differences in TPMT activity help account for the variability in tolerance to thiopurines. Rare and common genetic polymorphisms influence enzyme function resulting in a trimodal population distribution of activity. In Caucasians, complete TPMT deficiency occurs in 1 in 300 individuals. Carriers of a deficiency-associated allele (heterozygotes) have around 50\% enzyme activity and occur at an approximate frequency of 1 in 10 of the population. ${ }^{10}$ The majority of cases of TPMT deficiency $(\sim 95 \%)$ are associated with three alleles, TPMT*2, TPMT*3A and TPMT*3C. ${ }^{11}$ The frequency of these variants depends on ethnicity with TPMT*3A being more common in Caucasian populations. ${ }^{12}$

Individuals with complete TPMT deficiency who receive standard doses of AZA or MP are highly likely to develop severe and potentially fatal myelosuppression. There is a small case series of patients with IBD treated with around $10 \%$ of standard doses, all of whom tolerated this well. ${ }^{13}$ Heterozygotes are also at risk of toxicity at standard doses but this is prevented by initiation at $50 \%$ of the conventional dose. Hence, recommended practice is to check TPMT levels prior to starting therapy and adjusting the dose according to TPMT status.

Ultrahigh TPMT ( $>40 \mathrm{pmol} / \mathrm{mg} \mathrm{Hb} / \mathrm{h}$ ) is associated with a skewed drug metabolism in a selection of patients where MP is preferentially metabolised to methylmercaptopurine (MeMP) resulting in lower TGNs which in turn are associated with a poorer clinical response and side effects. This preferential metabolism to MeMP or 'shunting' is known as hypermethylation. ${ }^{14}$

TPMT phenotyping by enzyme assay is generally preferred to genotyping, as the assay will detect all completely deficient patients, irrespective of whether the patient has a rare or common variant TPMT genotype. Other factors influencing TPMT activity, for example red cell age, also result in discordance between genotype and phenotype, particularly in the high carrier range. ${ }^{15}$

\section{THIOGUANINE NUCLEOTIDES}

Although important, TPMT polymorphisms account for only $10 \%$ of overall thiopurine toxicity. ${ }^{16}$ Indeed, $50-75 \%$ of all patients developing leucopenia have a normal TPMT and only 3\% of hypermethylators have ultrahigh TPMT. ${ }^{17}$ Measuring TGNs provides a summary of epigenetic and genetic factors influencing thiopurine metabolism and, together with measurement of MeMP, offers a means for therapeutic drug monitoring.

Measurement of TGNs and MeMP in red blood cells (RBCs) has been shown to be clinically useful after steady state is reached at 4-6 weeks. ${ }^{18}$ Meta-analyses suggest that a therapeutic range of TGN between $235 \mathrm{pmol} / 8 \times 10^{8}$ and $450 \mathrm{pmol} / 8 \times 10^{8}$ RBCs correlates best with a good clinical response. ${ }^{19} 20$ In addition, there is evidence that TGN monitoring in IBD is associated with improved outcomes with a negative correlation between RBC TGNs and disease activity. ${ }^{21}$ A treatment strategy using TGNs to determine optimal dosing resulted in improved outcomes in $90 \%$ of patients compared with $33 \%$ in those not guided by TGNs. ${ }^{18}$

\section{HYPERMETHYLATION}

Approximately $15-20 \%$ of patients with IBD demonstrate hypermethylation when treated with thiopurines. ${ }^{16}$ The usual definition of hypermethylation is a 
ratio of MeMP to TGN of $>11$. In this setting, subtherapeutic TGNs risk a poor response to therapy. Moreover, MeMP $>5700 \mathrm{pmol} / 8 \times 10^{8} \mathrm{RBCs}$ results in a higher risk of hepatotoxicity. ${ }^{20}$

Allopurinol is a xanthine oxidase inhibitor that prevents the breakdown of thiopurines into thiouric acid (TUA). It was designed to increase the bioavailability of MP by preventing degradation to TUA. The combination of low dose thiopurine and $100 \mathrm{mg}$ of allopurinol (LDTA) corrects hypermethylation in patients who have failed therapy due to hepatotoxicity or who have had a poor response to treatment in association with subtherapeutic TGNs. ${ }^{14}{ }^{22}$ When using the combination, the administered dose of AZA or MP is reduced to $25-50 \%$ of the standard monotherapy dose. $^{23}$

Allopurinol is a safe drug with the main side effects including rashes and gastrointestinal (GI) symptoms but it can rarely $(1: 100000)$ cause life-threatening toxic epidermal necrolysis. ${ }^{24}$

\section{A PRACTICAL GUIDE TO THIOPURINE TREATMENT}

Prior to commencing thiopurines, patients should be screened to help prevent opportunistic infections as per European guidelines (see table 1). In addition, the pneumococcal vaccination is given before starting treatment and the influenza vaccine annually. ${ }^{25}$ Patients are advised that while on treatment they should not have 'live' vaccines. The more common 'live' vaccines include yellow fever; measles, mumps and rubella; and BCG (tuberculosis vaccine). The IBD passport is a good source of information for both patients and prescribers on foreign travel with IBD. ${ }^{26}$

Epstein-Barr virus (EBV) seronegativity in patients commencing thiopurines has long been a concern and it was identified in 2002 that treatment in this setting was associated with a small increased risk of EBV-positive lymphomas. ${ }^{27}$ More recently in the CESAME observational cohort, thiopurine treatment had an HR of 5.28 for developing lymphoproliferative

Table 1 Screening prior to thiopurine treatment ${ }^{25}$

\begin{tabular}{|c|c|}
\hline Investigations & Action \\
\hline Hepatitis C antibody & $\begin{array}{l}\text { Recommend treatment under } \\
\text { specialist guidance if positive. }\end{array}$ \\
\hline $\begin{array}{l}\text { Hepatitis B surface antigen } \\
\text { (HBsAg), hepatitis B surface } \\
\text { antibody (Anti-HBAbs), hepatitis B } \\
\text { core antibody (anti-HBcAb) }\end{array}$ & $\begin{array}{l}\text { Vaccinate the patient if negative. } \\
\text { Treatment with reverse transcriptase } \\
\text { inhibitors if positive. }\end{array}$ \\
\hline HIV & $\begin{array}{l}\text { Recommend treatment under } \\
\text { specialist guidance if positive. }\end{array}$ \\
\hline $\begin{array}{l}\text { Varicella zoster lgG (if no history } \\
\text { of infection) }\end{array}$ & $\begin{array}{l}\text { Vaccinate the patient if negative at } \\
\text { least } 3 \text { weeks prior to starting } \\
\text { treatment. }\end{array}$ \\
\hline Epstein-Barr virus (EBV) & $\begin{array}{l}\text { Testing (EBV IgG) recommended. } \\
\text { Stop thiopurine and consider } \\
\text { antivirals (ganciclovir or foscarnet) in } \\
\text { an acute infection. }{ }^{25}\end{array}$ \\
\hline
\end{tabular}

disorders with EBV infection being a further risk factor. ${ }^{28}$ The risk remains small and as yet, avoidance of these drugs in seronegative individuals is not advised. European guidelines suggests considering anti-TNF monotherapy as opposed to combination therapy with thiopurines. ${ }^{25}$

\section{OPTIMISING CLINICAL RESPONSE}

Measuring TGNs has been proven to improve clinical outcomes. ${ }^{18}$ We check TGNs in all patients who have symptoms or active disease. We also check TGNs 4 weeks after starting thiopurines or following a change in the dose (see figure 2). The onset of response from thiopurines is around 16 weeks so if being prescribed as monotherapy, bridging with corticosteroids or an alternative therapy should be considered. ${ }^{29}$

Where TGNs are subtherapeutic, increasing the dose by between $25 \mathrm{mg}$ and $50 \mathrm{mg}$ may be enough for TGNs to reach the therapeutic range. If patients are hypermethylating, and TGNs subtherapeutic, we recommend either switching to LDTA or dose splitting. The rationale behind dose splitting is that the reduced dose of thiopurine is below the optimum substrate affinity for TPMT. In a review of 20 patients with baseline MeMP levels greater than $7000 \mathrm{pmol} /$ $8 \times 10^{8}$ RBCs, dose splitting resulted in a significant decrease in MeMP levels without reducing TGNs. ${ }^{30}$

\section{MANAGING SIDE EFFECTS}

There are a number of different strategies employed when addressing adverse effects experienced on thiopurines which are discussed below (see figure 3 ).

For side effects other than pancreatitis, switching to LDTA achieves clinical remission in $78 \%$ of patients and has been found to reduce levels of MeMP while increasing TGNs to within therapeutic range. ${ }^{24}$ The

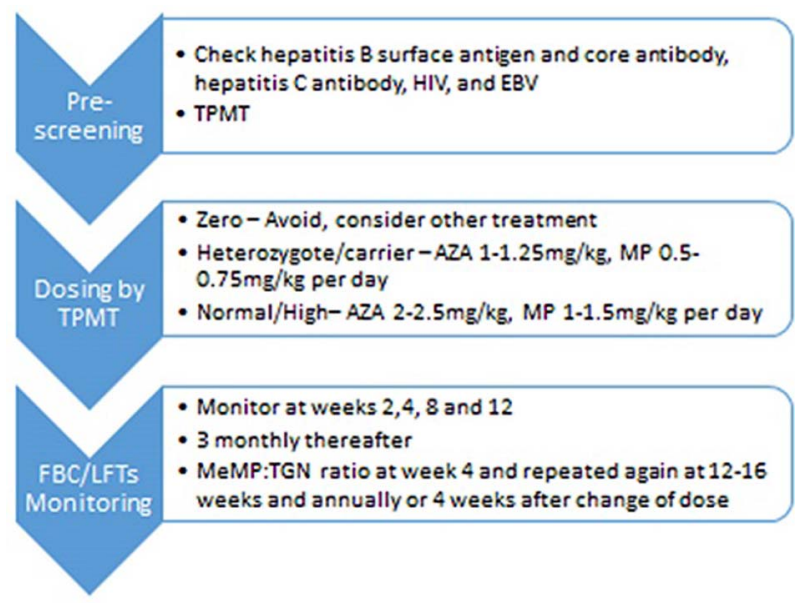

Figure 2 The pathway for commencement of thiopurines and monitoring. AZA, azathioprine; EBV, Epstein-Barr virus; MeMP, methylmercaptopurine; MP, mercaptopurine; $F B C$, full blood count; LFTs, liver function tests; TGN, thioguanine nucleotide; TPMT, thiopurine S-methyl transferase. 


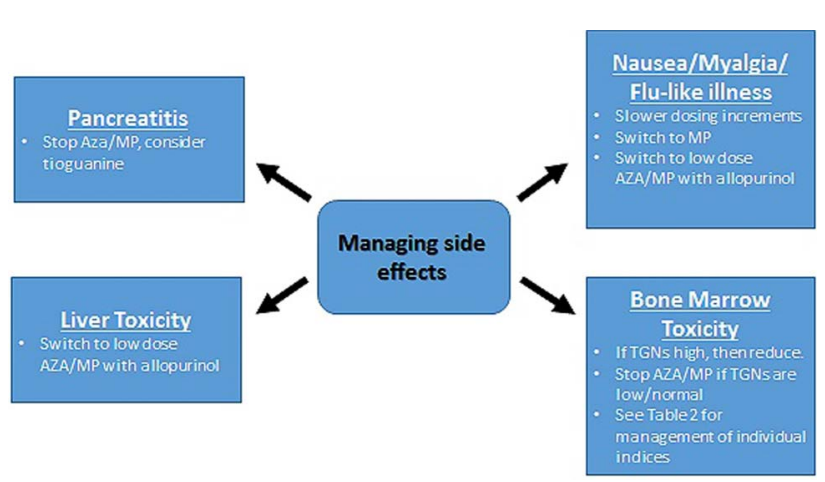

Figure 3 Management of adverse side effects in the context of MeMP:TGN monitoring. AZA, azathioprine; MeMP, methylmercaptopurine; MP, mercaptopurine; TGN, thioguanine nucleotides.

lowest available doses of AZA and MP come in a liquid form at $10 \mathrm{mg} / \mathrm{mL}$ and $20 \mathrm{mg} / \mathrm{mL}$, respectively, both of which are off-licence. For logistical reasons we advise patients who need to take the lowest dose to take $1.5 \mathrm{~mL} / 1 \mathrm{~mL}$ of AZA alternate days or halve a $25 \mathrm{mg}$ tablet of MP (12.5 mg).

\section{GASTROINTESTINAL SIDE EFFECTS}

Nausea is common with thiopurines. Changing the timing of the dose from morning to later in the day or at night can sometimes alleviate this. Switching to MP is well recognised to circumvent some cases of AZA induced nausea. ${ }^{31} \mathrm{~A}$ further option is to increase the dose of thiopurine gradually over 2-4 weeks rather than start at the maximum dose. Finally, switching to LDTA has been proven to successfully circumvent nausea in over a half of patients. ${ }^{24}$

\section{BONE MARROW TOXICITY}

Myelosuppression has been associated with low TPMT activity and with MeMP $>11450 \mathrm{pmol} / 8 \times 10^{8}$ RBCs. ${ }^{32}$ In this scenario, we adopt the same approach to that of hypermethylation and hepatotoxicity and switch to LDTA. Where leucopenia occurs in the absence of hypermethylation, our practice is to alter dosing according to relevant blood count parameters (see figure 4). In the case of lymphopenia, adjustment is debateable, as studies suggest patients with lymphopenia are not at increased risk of infections. ${ }^{33}$

\section{HEPATOTOXICITY}

Four per cent of patients experience thiopurine related hepatotoxicity. If this occurs the drug should be stopped until the liver function tests have normalised followed by commencing LDTA. MeMP levels $>5700 \mathrm{pmol} / 8 \times 10^{8} \mathrm{RBCs}$ have been associated with a threefold increase in the risk of hepatotoxicity. ${ }^{20}$ However, a proportion of patients develop hepatotoxicity in the absence of hypermethylation. Interestingly, in these patients, hepatotoxicity is also successfully circumvented in most cases by switching to LDTA.

\section{PANCREATITIS}

In the $3 \%$ of patients who develop pancreatitis, thiopurines are immediately stopped. Reports of successful rechallenge or switch to MP have been published, but, in general, the risk of repeat pancreatitis is high and we do not therefore recommend rechallenge with AZA or MP in this setting. Tioguanine, however, at doses of $20-40 \mathrm{mg}$, is an alternative to AZA and MP, which successfully avoids pancreatitis and is associated with reported clinical remission rates as high as $79 \%$ at 12 months. ${ }^{34}$

\section{OTHER CONSIDERATIONS}

The use of thiopurines as concomitant therapy alongside biologics has been shown to reduce antidrug antibody formation. ${ }^{4}$ The therapeutic range for this is not known. Recent studies have suggested that aiming for lower TGNs in this setting is equally efficacious. ${ }^{35-37}$

There are good safety data on the use of thiopurines in pregnancy and around the time of conception for women and men and their use is supported by European guidelines. ${ }^{38} 39$ There are however no safety data on the use of allopurinol in pregnancy. We advise the continued use of thiopurines throughout pregnancy after careful discussion with the patient. We avoid starting allopurinol during pregnancy and

\begin{tabular}{|l|l|}
\hline Full blood count indices & Action for thiopurine drug therapy \\
\hline WBC $2.5-3.5 \times 10^{9} / \mathrm{L}$ (mild) & Check metaboltes, monitor or consider reducing dose \\
\hline WBC $1.5-2.5 \times 10^{9} / \mathrm{L}$ (moderate) & $\begin{array}{l}\text { Stop drug for } 1 \text { week and restart at a lower dosewith weekly } \\
\text { FBC monitoring }\end{array}$ \\
\hline WBC $<1.5 \times 10^{9} / \mathrm{L}$ (severe) & Withdraw treatment \\
\hline Lymphopenia $0.5-1.5 \times 10^{9} / \mathrm{L}$ (mild-moderate) & Observe, correct metabolites \\
\hline Lymphopenia $<0.5 \times 10^{9} / \mathrm{L}$ (severe) & Reduce dose \\
\hline Neutropenia $1-1.5 \times 10^{9} / \mathrm{L}$ (mild) & Observe, correct metabolites \\
\hline Neutropenia $<1 \times 10^{9} / \mathrm{L}$ (moderate) & Withdraw treatment. If febrile, consider admitting for G-CSF \\
\hline Thrombocytopenia $<150 \times 10^{9} / \mathrm{L}$ & Observe, if ongoing screen for NRH \\
\hline Anaemia & $\begin{array}{l}\text { Check metaboltes, exclude nutritional deficiencies or } \\
\text { anaemia of chronic disease. If acute, exclude red cell aplasia }\end{array}$
\end{tabular}

Figure 4 The management of deranged full blood count (FBC) indices in patients on thiopurines. G-CSF, granulocyte colony stimulating factor; $\mathrm{NRH}$, nodular regenerative hyperplasia; WBC, white blood cell. 
would advise other treatments in situations where allopurinol would normally be used.

Most centres consider withdrawal after 5 years of treatment if the patient is in clinical remission. Treatment for over 4 years has been shown to increase the risk of non-melanoma skin cancer and lymphoma particularly in those patients over the age of 50 years. ${ }^{40}$ There is also an association between the longterm use of thiopurines, especially tioguanine, and nodular regenerative hyperplasia. Where thiopurines are withdrawn, 1 year clinical relapse rates are $23 \%$ in $\mathrm{CD}$ and $12 \%$ in UC. ${ }^{41}$

\section{CONCLUSION}

Thiopurines continue to be the mainstay of therapy for $\mathrm{CD}$ and moderate to severe UC. Thiopurine metabolite monitoring in addition to TPMT measurement successfully guides optimised therapy, reducing treatment failure from adverse effects or lack of clinical efficacy and is a classic example of the benefits of personalised medicine. These benefits are clearly evident in the treatment of IBD but should also be relevant across many other disciplines in which thiopurines are used as standard therapy.

Contributors Both BW and EJ wrote the manuscript with both MA-H and AM reviewing the biochemistry sections. PI and JS reviewed and supervised the clinical sections.

Competing interests None declared.

Provenance and peer review Not commissioned; internally peer reviewed.

Open Access This is an Open Access article distributed in accordance with the Creative Commons Attribution Non Commercial (CC BY-NC 4.0) license, which permits others to distribute, remix, adapt, build upon this work noncommercially, and license their derivative works on different terms, provided the original work is properly cited and the use is non-commercial. See: http://creativecommons.org/licenses/by$\mathrm{nc} / 4.0 /$

\section{REFERENCES}

1 Chevaux JB, Peyrin-Biroulet L, Sparrow MP. Optimizing thiopurine therapy in inflammatory bowel disease. Inflamm Bowel Dis 2011;17:1428-35.

2 Ardizzone S, Maconi G, Russo A, et al. Randomised controlled trial of azathioprine and 5-aminosalicylic acid for treatment of steroid dependent ulcerative colitis. Gut 2006;55:47-53.

3 Mowat C, Cole A, Windsor A, et al. Guidelines for the management of inflammatory bowel disease in adults. Gut 2011;60:571-607.

4 Chatu S, Subramanian V, Saxena S, et al. The role of thiopurines in reducing the need for surgical resection in Crohn's disease: a systematic review and meta-analysis. Am J Gastroenterol 2014;109:23-34; quiz 35.

5 Colombel JF, Sandborn WJ, Reinisch W, et al. Infliximab, azathioprine, or combination therapy for Crohn's disease. N Engl J Med 2010;362:1383-95.

6 Siegel CA, Sands BE. Review article: practical management of inflammatory bowel disease patients taking immunomodulators. Aliment Pharmacol Ther 2005;22:1-16.
7 Schwab M, Schäffeler E, Marx C, et al. Azathioprine therapy and adverse drug reactions in patients with inflammatory bowel disease: impact of thiopurine S-methyltransferase polymorphism. Pharmacogenetics 2002;12:429-36.

8 Dong XW, Zheng Q, Zhu MM, et al. Thiopurine $S$-methyltransferase polymorphisms and thiopurine toxicity in treatment of inflammatory bowel disease. World J Gastroenterol 2010;16:3187-95.

9 Thomas CW, Myhre GM, Tschumper R, et al. Selective inhibition of inflammatory gene expression in activated $\mathrm{T}$ lymphocytes: a mechanism of immune suppression by thiopurines. J Pharmacol Exp Ther 2005;312:537-45.

10 Weinshilboum RM, Sladek SL. Mercaptopurine pharmacogenetics: monogenic inheritance of erythrocyte thiopurine methyltransferase activity. Am J Human Genetics 1980;32:651-62.

11 Appell ML, Berg J, Duley J, et al. Nomenclature for alleles of the thiopruine methyltransferase gene. Pharmacogenet Genomics 2013;23:242-8.

12 Collie-Duguid ES, Pritchard SC, Powrie RH, et al. The frequency and distribution of thiopurine methyltransferase alleles in Caucasian and Asian populations. Pharmacogenetics 1999;9:37-42.

13 Kaskas BA, Louis E, Hindorf U, et al. Safe treatment of thiopurine S-methyltransferase deficient Crohn's disease patients with azathioprine. Gut 2003;52:140-2.

14 Blaker PA, Arenas-Hernandez M, Smith MA, et al. Mechanism of allopurinol induced TPMT inhibition. Biochem Pharmacol 2013;86:539-47.

15 Lennard L, Chew TS, Lilleyman JS. Human thiopurine methyltransferase activity varies with red blood cell age. $\mathrm{Br}$ J Clin Pharmacol 2001;52:539-46.

16 Ansari A, Arenas M, Greenfield SM, et al. Prospective evaluation of the pharmacogenetics of azathioprine in the treatment of inflammatory bowel disease. Aliment Pharmacol Ther 2008;28:973-83.

17 Colombel JF, Ferrari N, Debuysere H, Genotypic analysis of thiopurine S-methyltransferase in patients with Crohn's disease and severe myelosuppression during azathioprine therapy. Gastroenterology 2000;118:1025-30.

18 Smith M, Blaker P, Patel C, et al. The impact of introducing thioguanine nucleotide monitoring into an inflammatory bowel disease clinic. Int J Clin Pract 2013;67:161-9.

19 Moreau AC, Paul S, Del Tedesco E, et al. Association between 6-thioguanine nucleotides levels and clinical remission in inflammatory disease: a meta-analysis. Inflamm Bowel Dis 2014;20:464-71.

20 Dubinsky MC, Lamothe S, Yang HY, et al. Pharmacogenomics and metabolite measurement for 6-mercaptopurine therapy in inflammatory bowel disease. Gastroenterology 2000;118:705-13.

21 Cuffari C, Théorêt Y, Latour S, et al. -Mercaptopurine metabolism in Crohn's disease: correlation with efficacy and toxicity. Gut 1996;39:401-6.

22 Ansari A, Patel N, Sanderson J, et al. Low-dose azathioprine or mercaptopurine in combination with allopurinol can bypass many adverse drug reactions in patients with inflammatory bowel disease. Aliment Pharmacol Ther 2010;31:640-7.

23 Sparrow MP, Hande SA, Friedman S, et al. Allopurinol safely and effectively optimizes tioguanine metabolites in inflammatory bowel disease patients not responding to azathioprine and mercaptopurine. Aliment Pharmacol Ther 2005;22:441-6. 
24 Halevy S, Ghislain PD, Mockenhaupt M, et al. EuroSCAR Study Group. Allopurinol is the most common cause of Stevens-Johnson syndrome and toxic epidermal necrolysis in Europe and Israel. J Am Acad Dermatol 2008;58:25-32.

25 Rahier JF, Ben-Horin S, Chowers Y, et al. European evidence-based Consensus on the prevention, diagnosis and management of opportunistic infections in inflammatory bowel disease. J Crohns Colitis 2009;3:47-91.

26 http://www.ibdpassport.com

27 Dayharsh GA, Loftus EV, Sandborn WJ, et al. Epstein-Barr virus-positive lymphoma in patients with inflammatory bowel disease treated with azathioprine or 6-mercaptopurine. Gastroenterology 2002;122:72-7.

28 Sokol H, Beaugerie L, Maynadié M, et al. Excess primary intestinal lyphoproliferative disorders in patients with inflammatory bowel disease. Inflammatory Bowel Disease 2012;18:2063-71.

29 Prefontaine E, Macdonald JK, Sutherland LR. Azathioprine or 6-mercaptopurine for induction of remission in Crohn's disease. Cochrane Database Syst Rev 2010;(6):CD000545.

30 Shih DQ, Nguyen M, Zheng L, et al. Split-dose administration of thiopurine drugs: a novel and effective strategy for managing preferential 6-MMP metabolism. Aliment Pharmacol Ther 2012;36:449-58.

31 Kennedy NA, Rhatigan E, Arnott ID, et al. A trial of mercaptopurine is a safe strategy in patients with inflammatory bowel disease intolerant to azathioprine: an observational study, systematic review and meta-analysis. Aliment Pharmacol Ther 2013;38:1255-66.

32 Hindorf $\mathrm{U}$, Lindqvist $\mathrm{M}$, Hildebrand $\mathrm{H}$, et al. Adverse events leading to modification of therapy in a large cohort of patients with inflammatory bowel disease. Aliment Pharmacol Ther 2006;24:331-42.

33 Vögelin M, Biedermann L, Frei P, et al. The impact of azathioprine-associated lymphopenia on the onset of opportunistic infections in patients with inflammatory bowel disease. PLoS ONE 2016;11:e0155218.

34 Bonaz B, Boitard J, Marteau P, et al., Getaid. Tioguanine in patients with Crohn's disease intolerant or resistant to azathioprine/mercaptopurine. Aliment Pharmacol Ther 2003;18:401-8.

35 Van Schaik T, Maljaars JP, Roopram RK, et al. Influence of combination therapy with immune modulators on anti-TNF trough levels and antibodies in patients with IBD. Inflamm Bowel Dis 2014;20:2292-8.

36 Yarur AJ, Kubiliun MJ, Czul F, et al. Concentrations of 6-thioguanine nucleotide correlate with trough levels of infliximab in patients with inflammatory bowel disease on combination therapy. Clin Gastroenterol Hepatol $2015 ; 13: 1118-24 . e 3$

37 Cahill J, Zadvornova Y, Naik AS, et al. Tu1282 azathioprine or 6-mercaptopurnine dose does not effect serum infliximab level or rate of antibody to infliximab formation. Gastroenterology 2015;148:S-847.

38 Coelho J, Beaugerie L, Colombel JF, et al. Pregnancy outcome in patients with inflammatory bowel disease treated with thiopurines:cohort from the CESAME Study. Gut 2011;60:198-203.

39 Teruel C, López-San Román A, Bermejo F, et al. Outcomes of pregnancies fathered by inflammatory bowel disease patients exposed to thiopurines. Am J Gastroenterology 2010;105:2003-8.

40 Beigel F, Steinborn A, Schnitzler F, et al. Risk of malignancies in patients with inflammatory bowel disease treated with thiopurines or anti-TNF alpha antibodies. Pharmacoepidemiol Drug Saf 2014;23:735-44.

41 Kennedy NA, Kalla R, Warner B, et al. Thiopurine withdrawal during sustained clinical remission in inflammatory bowel disease: relapse and recapture rates, with predictive factors in 237 patients. Aliment Pharmacol Ther 2014;40:1313-23. 